\title{
Structure and mechanical properties of $\mathrm{Ti}-\mathrm{C}$ films deposited using combination of pulsed DC and normal DC magnetron co-sputtering
}

\author{
K.H.T. Raman a , M.S.R.N. Kiran ${ }^{b}$, U. Ramamurty $^{\mathrm{b}}$, G. Mohan Rao ${ }^{\mathrm{a}, *}$ \\ a Department of Instrumentation and Applied Physics, Indian Institute of Science, Bangalore 560 012, India \\ ${ }^{\mathrm{b}}$ Department of Materials Engineering, Indian Institute of Science, Bangalore 560 012, India
}

\section{A R T I C L E I N F O}

\section{Article history:}

Received 12 April 2012

Received in revised form 11 May 2012

Accepted 12 May 2012

Available online 18 May 2012

\section{Keywords:}

Titanium carbide

Pulsed balanced magnetron

Preferred orientation

Nanocomposite

Nanoindentation

\begin{abstract}
A B S T R A C T
Titanium-carbon (Ti-C) thin films of different compositions were prepared by a combination of pulsed DC (for Ti target) and normal DC (for graphite target) magnetron co-sputtering on oxidized silicon and fused quartz substrates. At 33.7 at.\% of C content, pure hcp Ti transforms into fcc-TiC with a preferential orientation of (220) along with (111) and (200). A clear transformation in the preferential orientation from (220) to (111) has been observed when the $C$ content was increased to 56 at.\%. At 62.5 at.\% of $C$, $\mathrm{TiC}$ precipitates in an amorphous carbon matrix whereas further increase in $\mathrm{C}$ leads to $\mathrm{X}$-ray amorphous films. The cross-sectional scanning electron microscope images reveal that the films with low carbon content consists of columnar grains, whereas, randomly oriented grains are in an amorphous carbon matrix at higher carbon content. A dramatic variation was observed in the mechanical properties such as hardness, $H$, from 30 to $1 \mathrm{GPa}$ and in modulus, $E$, from 255 to $25 \mathrm{GPa}$ with varying carbon content in the films. Resistance to plastic deformation parameter was observed as 0.417 for films containing 62.5 at.\% of C. Nanoscratch test reveals that the films are highly scratch resistant with a coefficient of friction ranging from 0.15 to 0.04 .
\end{abstract}

(C) 2012 Elsevier B.V. All rights reserved.

\section{Introduction}

Titanium carbide (TiC) is one of the most widely used hard coating materials. Interestingly, its chemical bonding is similar as transition metal nitrides showing mixed covalent, metallic and ionic characters [1], which results in good mechanical, thermal, tribological and electrical properties [1-3]. Its high electrical conductivity makes it a suitable candidate for Ohmic contacts in microelectronic devices [2,4] and organic light emitting diodes (OLEDS) [5]. In electro-chemical industries, TiC is used as anode in batteries and super capacitors [6,7], where the coating should be dense and with a high surface area. In addition, TiC is an alternate to platinum as a catalyst and a first wall in nuclear reactor $[8,9]$, and diffusion barrier in semiconductor technology [2,3].

A wide variety of techniques have been used to synthesize transition metal carbide (TiC, $\mathrm{ZrC}$, TaC, etc.) films [1]. Among these, a well established and industry adopted technique is the physical vapor deposition (PVD) based on sputtering [10]. There have been several sputtering techniques such as unbalanced magnetron sputtering (UBMS), balanced magnetron sputtering and closed field unbalanced magnetron sputtering (CFUBMS) used to deposit these ceramic films [11-13]. These techniques are useful to control the

\footnotetext{
* Corresponding author. Tel.: +91 802293 2349; fax: +91 8023600135

E-mail address: gmrao@isu.iisc.ernet.in (G.M. Rao).
}

coating properties such as coating density, microstructure and mechanical properties [14,15]. In CFUBMS and UBMS techniques, the ionization efficiency of the reactive/inert gas is relatively high. Hence, the probability of higher ion energy bombardment to the growing film is high, which in turn enhances the defect density in the coatings [16]. Another disadvantage with UBMS is that the flux of escaping electrons is not uniform, thus plasma generated is non uniform and it leads to non uniform density in the coating [17]. In pulsed magnetron sputtering, tuning the mechanical property of the coating is possible and hence it is accepted as leading technology in industry [18]. The principle advantage of balanced magnetron sputtering (BMS) is that a dense plasma can be formed nearer to cathode at low pressures so that ions can be accelerated from the plasma to cathode without loss of energy and this allows high sputter rate with lower cathode potential [17]. Compared with other magnetron configuration, BMS configuration gives uniform vapor flux and ion bombardment on growing film is less $[17,19]$. Till now, the best reported values of hardness for $\mathrm{TiC} / \mathrm{a}-\mathrm{C}$ films are 35 and $29 \mathrm{GPa}$, for the films synthesized using CFUBMS and pulsed CFUBMS with a substrate biasing of $-291 \mathrm{~V}$ and $-50 \mathrm{~V}$, respectively $[20,21]$.

In this paper, we report on the deposition of non-stoichiometric $\mathrm{Ti}-\mathrm{C}$ thin films using a technique that combines Pulsed DC and DC non-reactive balanced magnetron co-sputtering (PBMS) and without applying any substrate bias. Our experimental results show that the deposited films have different orientation and microstructure, 
dense microstructure, better mechanical and tribological properties.

\section{Experimental}

The deposition of the non-stoichiometric TiC was carried out in high vacuum chamber (base pressure $1.0 \times 10^{-5} \mathrm{mbar}$ ) by nonreactive PBMS. A $75 \mathrm{~mm}$ dia titanium target (99.9\% purity) was operated with Pulsed DC power supply (HUTTINGER Electronics, $\mathrm{GmBH})$ and a $100 \mathrm{~mm}$ dia graphite target $(99.9 \%)$ was operated with DC power supply (HUTTINGER Electronics, GmBH). The pulsed DC frequency was maintained at $100 \mathrm{kHz}$. By tuning the cathode current density, films with different $\mathrm{C}$ and $\mathrm{Ti}$ concentration were prepared. Sputtering was carried out at a constant pressure of $2.0 \times 10^{-3}$ mbar, with the Ar flow rate maintained at $6 \mathrm{sccm}$. The target-substrate distance was maintained as $130 \mathrm{~mm}$ for all the depositions. Thickness for all the films was maintained to be $1.2 \mu \mathrm{m}$. While the films deposited on fused quartz were used for $\mathrm{X}$-ray diffraction (XRD) studies, films deposited on oxidized Si (oxidized at $600^{\circ} \mathrm{C}$ in presence of oxygen) substrates were used for nanoindentation, scanning electron microscopy (SEM) and X-ray photo electron spectroscopy (XPS). The substrate temperature was kept at $350^{\circ} \mathrm{C}$ during deposition. Crystal structure of the deposited films was analyzed with XRD using Advanced D8 (Bruker AXS). Deposition rates were optimized using Dektak 150 stylus profilometer of Veeco Instruments). The microstructure of the films was analyzed using FE-SEM (SIRION, FEI Company). Elemental composition and binding energy was analyzed using X-ray photoelectron spectroscopy (SPECS GmbH spectrometer with Phobios 100MCD Energy analyzer) and data acquisitions were done after sputter etching the samples to a depth of 70-80 $\mathrm{A}$.

Mechanical properties of the films were investigated using a nanoindenter (Triboindenter of Hysitron, Minneapolis, USA) with an in situ imaging capability. The machine continuously monitors and records the load, $P$, and displacement, $h$, of the indenter with force and displacement resolutions of $1 \mathrm{nN}$ and $0.2 \mathrm{~nm}$, respectively. A Berkovich (three sided pyramidal) diamond indenter with a tip radius of $\sim 100 \mathrm{~nm}$ was used to indent the films. In order to identify flat regions for the experiment, the films surfaces were imaged prior to indentation using the same indenter tip. A loading and unloading rate of $0.8 \mathrm{mN} / \mathrm{s}$ and a hold time of $10 \mathrm{~s}$ at peak load were employed. A minimum of fifteen indentations was performed on each film. To avoid the overlapping of plastic zones of two neighboring indentations, a distance of 10 times the diagonal length of the indentation was maintained between two indentations. Coefficient of friction was evaluated using the same machine in scratch test mode with a conospherical tip of $1 \mu \mathrm{m}$ diameter. Scratch load increased from 0 to $3 \mathrm{mN}$ in $30 \mathrm{~s}$ for a scratch length of $10 \mu \mathrm{m}$.

\section{Results and discussion}

Fig. 1 shows the XRD patterns of non-stoichiometric TiC thin films deposited on fused quartz. Fig. 1(a) shows the XRD pattern for the film with 33.7 at.\% C and it consists of Ti rich TiC with (2 20 ) as preferred orientation and the corresponding XPS spectrum (Figs. 2 and 3 ) shows the formation of Ti-C bond. However, the amorphous $\mathrm{C}-\mathrm{C}$ bonds are also present in the films but their bonding contribution with $\mathrm{Ti}$ is estimated as $\sim 30 \%$. Fig. 1(b) indicates the stoichiometric form of TiC with a preferred (111) orientation. The transformation of preferred orientation from (220) to (111) is attributed to an increase in the C content in the films to 56.8 at.\% and (111) oriented films shows higher wear resistance than other orientations [22]. With further increase of C to 62.5 at.\%, 34\% of TiC and remaining amorphous $C$ phases result. The XPS data shows that the carbon peak splits into two, with one peak belonging to elemental

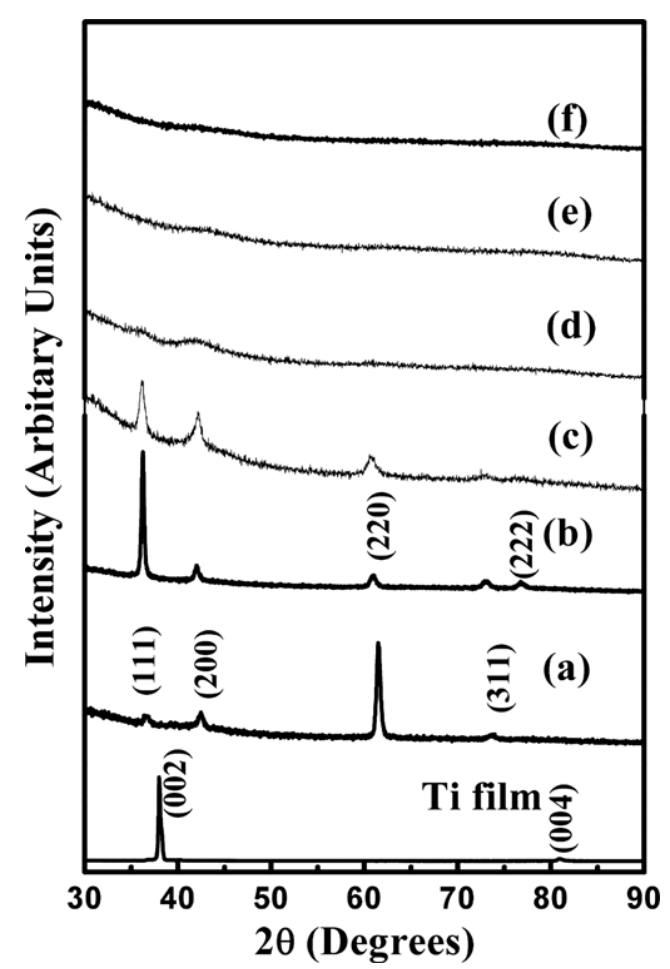

Fig. 1. X-ray diffraction patterns of $\mathrm{Ti}-\mathrm{C}$ films deposited on fused silica substrates for films having different carbon concentrations. Titanium film: (a) 33.7 at.\%, (b) 56.8 at.\%, (c) 62.5 at.\%, (d) 72.9 at.\%, (e) 87.1 at.\% and (f) 99.7 at.\%.

C and the other to bonded carbon (Ti-C) as shown Fig. 3(c) $[23,24]$. In addition, Fig. 1(c) also indicates an increase in the full width half maxima (FWHM) of all the crystallographic peaks implying that there is a commensurate decrease in the grain size of $15 \mathrm{~nm}$. A possible reason for the small grain size is the presence of a large

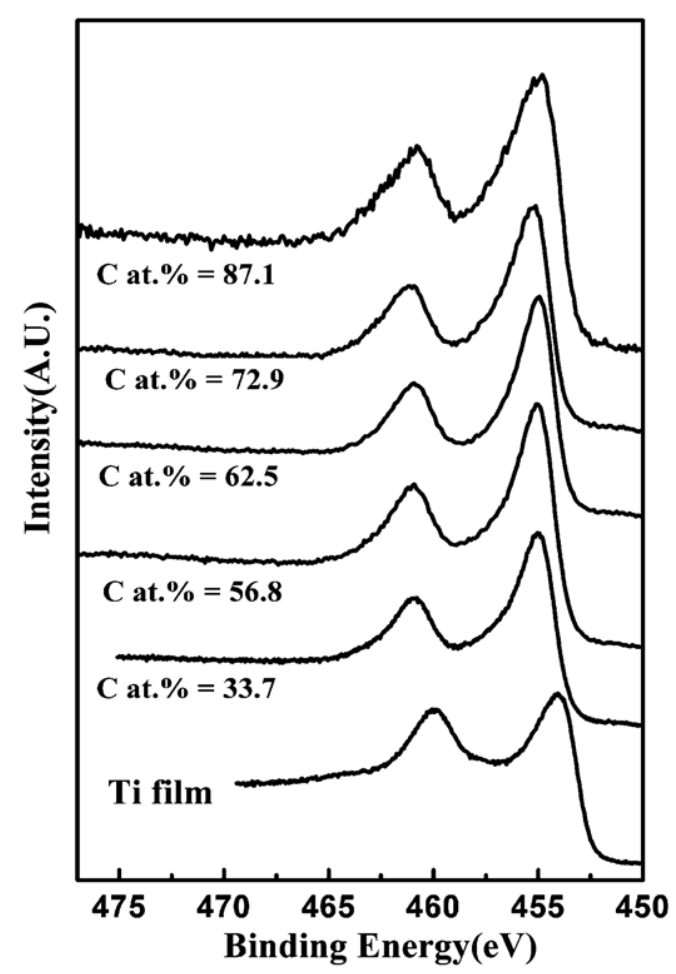

Fig. 2. Titanium $2 \mathrm{p}$ high resolution $\mathrm{X}$-ray photoelectron spectra for different carbon compositions. 

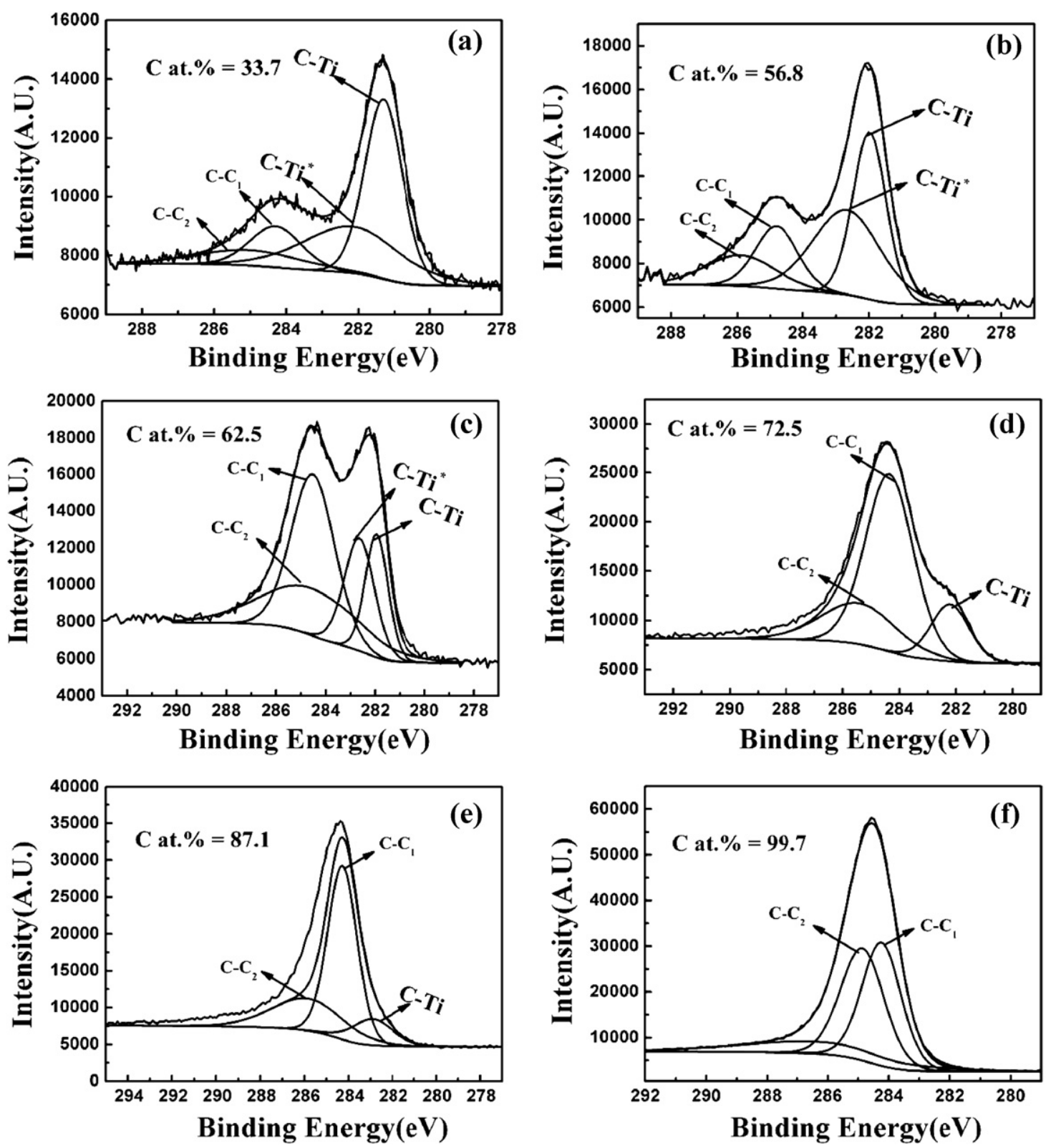

Fig. 3. Carbon core level X-ray photoelectron spectroscopy for different carbon composition.

amount of excess carbon in the films. This is because higher amount of carbon isolates the TiC crystallites and hinders their growth. A similar phenomenon has been reported earlier [13,21]. TiC precipitates out as small particles in an amorphous carbon matrix upon further increase of carbon to 72.9 at.\%, as shown in Fig. 1(d). The crystallite size is comparably small at this carbon concentration and XPS analysis shows that the unbonded carbon (a-C) peak intensity is much higher when compared with bonded carbon (Ti-C). Further increase in carbon content makes the films amorphous, as shown in Fig. 1(e and $\mathrm{f}$ ).

There are compelling differences in the surface morphologies of various films, which are displayed in Fig. 4. Fig. 4(a) shows the surface morphology of the films with low carbon content (33.7 at.\% of C). It indicates a smooth surface discontinued by unevenly dispersed large bumps. The corresponding cross-sectional image shown in Fig. 4(b) reveals that the film exhibits a columnar structure with the principal axis being perpendicular to the films and the substrate interface. Similar morphology and cross-section images are shown in Fig. 4(c and d) for films containing 56.8 at.\% C. These
Ti-rich, stoichiometric and dense coatings with columnar growth are extremely useful as electrical sliding contacts, diffusion barriers in microelectronics and corrosion resistant coatings. Fig. 4(e and f) shows surface morphology and cross-section of films containing 62.5 at.\% C. Moreover, it is clear from the cross-sectional image that the columnar growth is not significant. It is due to the fact that, at this particular composition, dispersed nanocrystals of $\mathrm{TiC}$ are embedded in amorphous carbon matrix and it was also confirmed by XPS results shown earlier in Fig. 3(c). The features indicating columnar growth disappear with the further increase of C. For nearly pure C coating (99.7 at.\%), the microstructure appears as highly porous with several micro cracks on the surface of the films as shown in Fig. 4( $\mathrm{g}$ and $\mathrm{h}$ ).

Representative $P-h$ curves of non-stoichiometric TiC thin films deposited with different compositions are shown in Fig. 5(a). Except for the pure carbon and titanium film, the maximum penetration depth of the indenter, $h_{\max }$, at the peak load of $8 \mathrm{mN}$ is less than $10 \%$ of the film thickness; therefore, it can be considered that the substrate's influence on the observed mechanical response is 

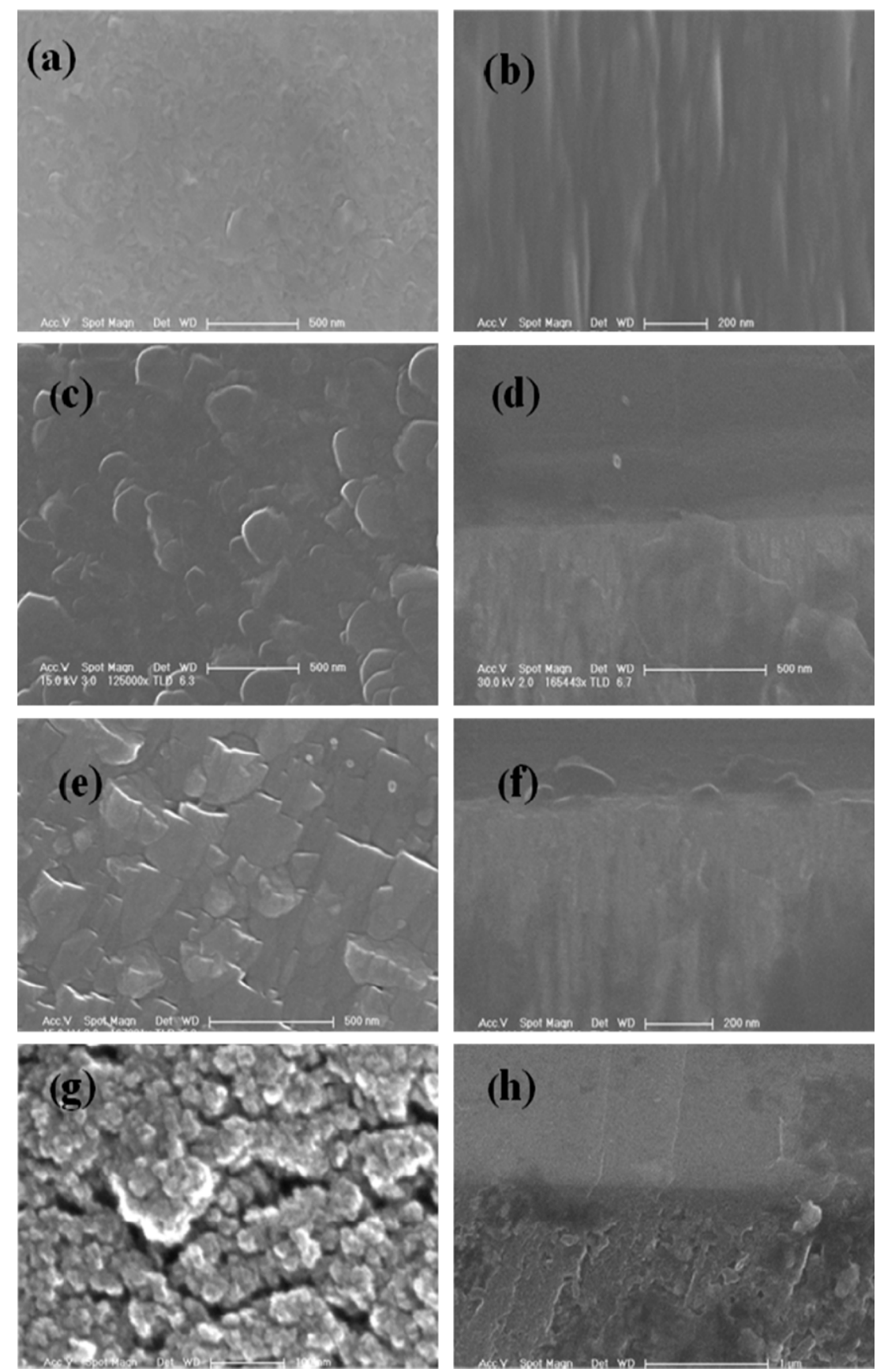

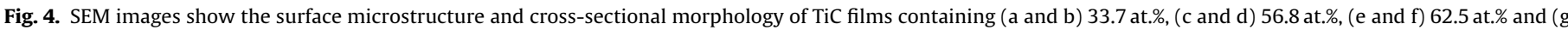
and h) 99.7 at.\% of carbon, respectively.

\section{Table 1}

Variation of cathode current density, deposition rate, grain size, Ti-C and $\mathrm{C}-\mathrm{C}$ bond density, hardness, reduced modulus, elastic strain to failure and resistance to plastic deformation parameter with varying carbon content in the Ti-C films.

\begin{tabular}{|c|c|c|c|c|c|c|c|c|c|c|}
\hline \multirow[t]{2}{*}{ Carbon (at.\%) } & \multicolumn{2}{|c|}{$\begin{array}{l}\text { Cathode current } \\
\text { density }\left(\mathrm{mA} / \mathrm{cm}^{2}\right)\end{array}$} & \multirow[t]{2}{*}{$\begin{array}{l}\text { Deposition rate } \\
(\mathrm{nm} / \mathrm{min})\end{array}$} & \multirow[t]{2}{*}{$\begin{array}{l}\text { Grain size } \\
(\mathrm{nm})\end{array}$} & \multicolumn{2}{|c|}{ Bonding\% } & \multirow[t]{2}{*}{$H(\mathrm{GPa})$} & \multirow[t]{2}{*}{$E_{r}(\mathrm{GPa})$} & \multirow[t]{2}{*}{$H / E_{r}$} & \multirow[t]{2}{*}{$H^{3} / E_{r}^{2}$} \\
\hline & $\mathrm{Ti}$ & $\mathrm{C}$ & & & $\mathrm{Ti}-\mathrm{C}$ & $C-C$ & & & & \\
\hline 0 & 10.96 & 0 & 8.8 & 36 & 0 & 0 & 0.95 & 110 & 0.007 & 0.00004 \\
\hline 33 & 10.96 & 2.46 & 9.5 & 19 & 90 & 10 & 19.2 & 210 & 0.091 & 0.16 \\
\hline 56.8 & 10.96 & 3.7 & 10 & 27 & 73 & 27 & 25 & 232 & 0.107 & 0.290 \\
\hline 62.5 & 10.96 & 6.17 & 11 & 15 & 34 & 66 & 30 & 255 & 0.117 & 0.415 \\
\hline 72.9 & 6.88 & 6.17 & 7.3 & 5 & 17 & 83 & 13.4 & 133 & 0.1 & 0.13 \\
\hline 87.1 & 4.38 & 6.17 & 6.4 & - & 12 & 88 & 9.9 & 99 & 0.1 & 0.099 \\
\hline 99.7 & 0 & 6.17 & 6.2 & - & 0 & 99.9 & 1 & 25 & 0.04 & 0.0016 \\
\hline
\end{tabular}



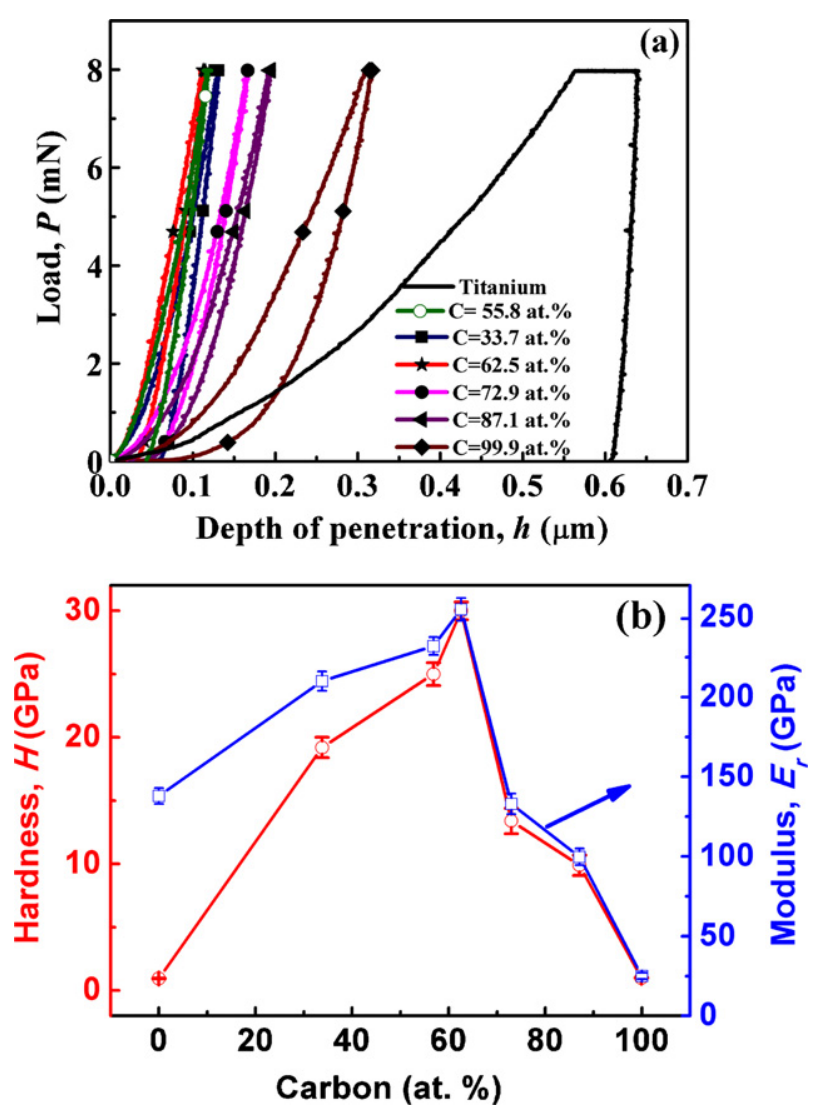

Fig. 5. (a) Representative load, $P$-displacement, $h$ curves, (b) variation of hardness, $H$ and elastic modulus, $E$ with varying Ti and $C$ composition in the films.

negligible. It is clear from the figure that indenter penetration depth and elastic recovery after unloading are completely dependent on the carbon content in the films. While the penetration depth is maximum for high carbon content films, it is lowest for the film with a carbon content of 62.5 at.\%. The mechanical properties such as hardness $H$ and modulus $E$ calculated by fitting the unloading curve of the $P$ - $h$ curve using Oliver-Pharr method [25] are listed in Table 1.

Fig. 5(b) show the variation of $H$ and $E$ with the $C$ content in the films, respectively and residual indent impressions after indentation, captured using atomic force microscope for different carbon compositions were shown in Fig. 6. The $H$ and $E$ for the pure Ti film were estimated as $0.95 \mathrm{GPa}$ and $110 \mathrm{GPa}$, respectively. At 33 at.\% $\mathrm{C}$, the hardness of the film is $\sim 19 \mathrm{GPa}$ which increases to $25 \mathrm{GPa}$ with an increasing $C$ content of 56.8 at.\%. The highest hardness of $\sim 30 \mathrm{GPa}$ was observed for films with a $\mathrm{C}$ content of 62.5 at.\%. A linear and precipitous decrease in $H$ values was observed with further increase in C. The highest hardness at 62.5 at.\% of carbon content in the films is possibly due to nanocomposite strengthening [26-29]. At this particular composition, it is clearly observed from XRD and XPS that nanocrystallites of TiC were embedded in the amorphous carbon matrix. It is known that amorphous carbon generally precipitates at the grain boundaries [26-29]. The combination of two factors: (a) large difference in the elastic moduli of the amorphous $\mathrm{C}$ and $\mathrm{TiC}$ and (b) the smaller grain size of $\mathrm{TiC}$, possibly led to the formation of nanocomposites with improved mechanical properties at this composition. This is not the case in films with low $\mathrm{C}$ content, wherein the grain sizes are comparatively large (FWHM of XRD pattern for different compositions as shown in Fig. 1) and also TiC is non-stoichiometric. On the other hand, with increasing $\mathrm{C}$ content in the films, the hardness decreases because of further reduction in grain size and the increased layer thickness of amorphous carbon [26-29]. Earlier, a maximum hardness of 35 GPa has

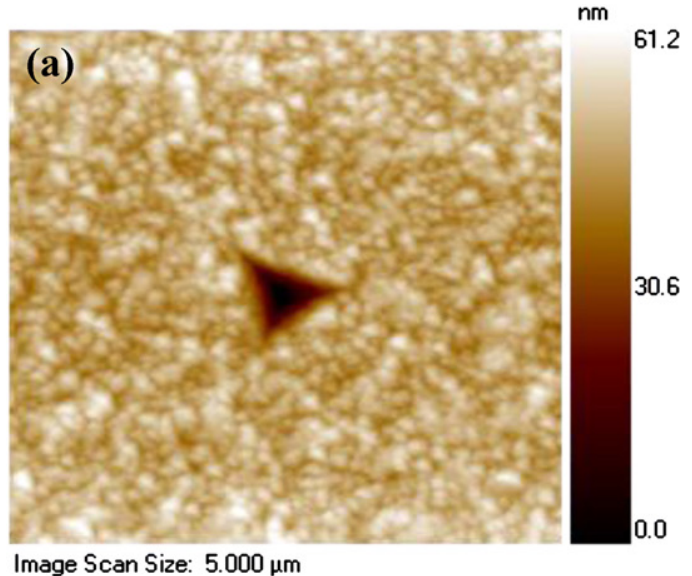

Image Scan Size: $5.000 \mu \mathrm{m}$
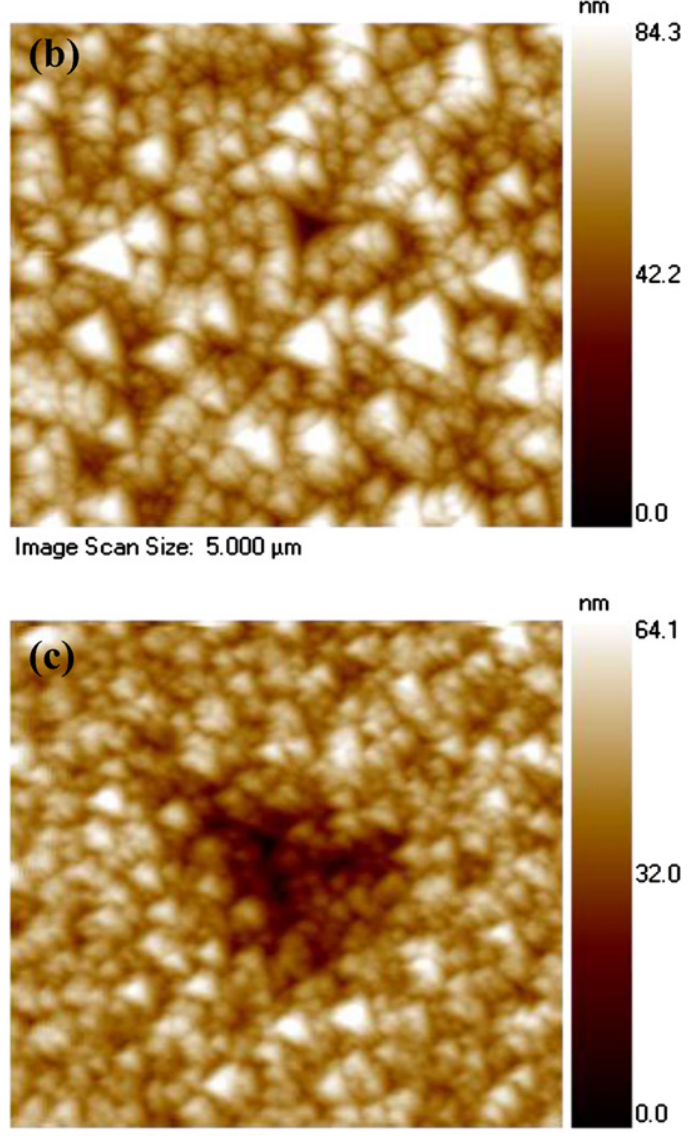

Image Scan Size: $5.000 \mu \mathrm{m}$

Fig. 6. Atomic force microscope images of the residual indent impressions for films containing different C concentrations: (a) $33.7 \%$, (b) $62.5 \%$, and (c) $99.7 \%$.

been reported for a similar composite, which was synthesized by using the CFUBMS technique with substrate biasing of -291 V [21]. In the case of films deposited by using pulsed CFUBMS but with a substrate biasing $-50 \mathrm{~V}$, a hardness of $29 \mathrm{GPa}$ has been obtained [20]. However, in the present case, we have deposited films without any substrate bias by means of pulsed DC balanced magnetron sputtering and achieved $H$ values as high as $\sim 30 \mathrm{GPa}$.

The variation of $E$ with the $C$ content exhibits a trend similar to that of variation of $H$, as shown in Fig. 5(b). A maximum $E$ value of $255 \mathrm{GPa}$ was observed for the films with 62.5 at.\% C content. Interestingly, both $H$ and $E$ are correlated with a linear relationship. Sometimes, this kind of relationship is an artifact where significant amount of pile-up or sink-in effects present around the indenter 


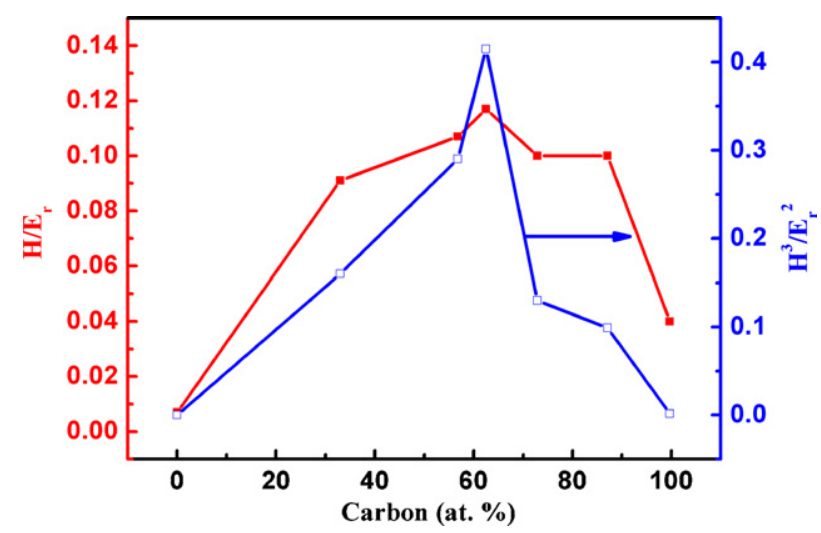

Fig. 7. Elastic strain to failure, $H / E_{r}$ and resistance to plastic deformation, $H^{3} / E_{r}^{2}$ with varying $\mathrm{Ti}$ and $\mathrm{C}$ composition in the films.

faces. However, images of the indentation impressions (see Fig. 6) revel no pile-up or sink-in, hence it is reasonable to conclude that the films which are hardest are also stiffest. Beyond the peak, $E$ decreases markedly, which is attributed to a decrease in the TiC crystal density and increase in amorphous carbon content.

Along with hardness, modulus can also have an important influence on wear behavior [28-30]. The ratio between $H$ and $E_{r}$ gives elastic strain to failure, which has shown to be a more suitable parameter for predicting the wear resistance. $H^{3} / E_{r}^{2}$ parameter gives information about resistance to plastic deformation in coatings. These parameters were calculated for all carbon compositions and tabulated in Table 1 and also shown as a graphical representation in Fig. 7. Films containing 62.5 at.\% carbon showed highest values of elastic strain to failure $\left(H / E_{r}=0.117\right)$ and resistance to plastic deformation $\left(H^{3} / E_{r}^{2}=0.419\right)$, and these values are much higher than reported earlier $[28,29]$.

Fig. 8 shows the variation of coefficient of friction, $\mu$, with varying $C$ content in the films. The maximum $\mu(0.15)$ was recorded for the film with 33.7 at.\% C content. With increasing C content to 62.5 at.\%, $\mu$ decreases to 0.08 and decreases further to 0.04 upon increasing the $\mathrm{C}$ content. In low $\mathrm{C}$ containing films, periodic and precipitous reductions in $\mu$ are noteworthy. These are possibly due to the presence of TiC grain boundaries embedded in an amorphous $\mathrm{C}$ matrix. Moreover, this kind of effect is more clearly seen in the films with carbon content of 62.5 at.\%. However, reduction in $\mu$ was not seen at higher carbon contents (i.e. from 72 to 99.9 at.\%), because of the absence of $\mathrm{TiC}$ nanocrystals and hence the movement of the indenter is smooth along lateral displacement. Fig. 9 shows AFM images of the scratched surfaces revealed that scratch tracks are almost invisible on the surfaces because the indenter

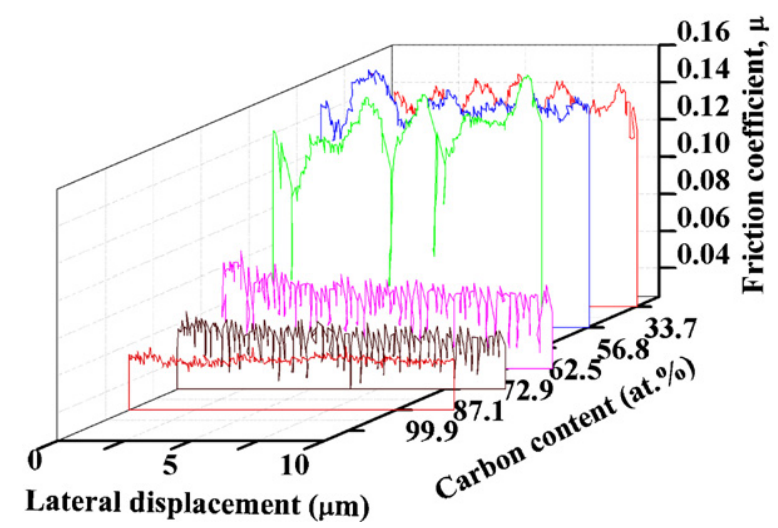

Fig. 8. Variation of coefficient of friction with varying $\mathrm{Ti}$ and $\mathrm{C}$ composition in the films.

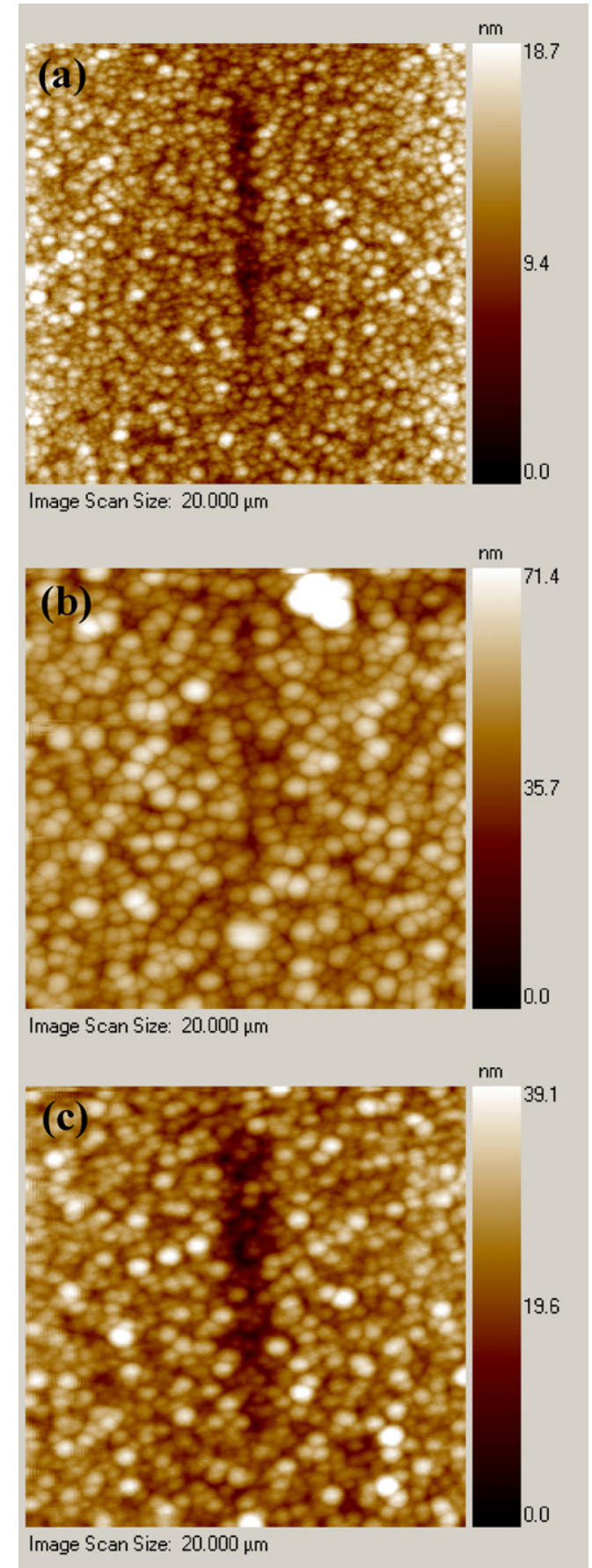

Fig. 9. Atomic force microscope images of the residual scratch impressions for films containing different C concentrations: (a) 33.7\%, (b) $62.5 \%$, and (c) $99.7 \%$.

slides smoothly on the film surfaces without much resistance and hence extremely low coefficient of friction.

\section{Conclusions}

Non-stoichiometric thin films of $\mathrm{Ti}-\mathrm{C}$ were prepared using pulsed DC and DC balanced magnetron co-sputtering technique and characterized using FE-SEM, XRD, XPS and nanoindenter experiments. Preferential orientation of the crystallites was shown to be completely dependent on the $C$ content in the films. At lower $C$ contents (220) was the preferred orientation and it transformed to (111) with a small increase of the amount of $C$ in the films. It was observed that the $C$ content in the films plays a major role 
in determining the microstructure and roughness of the films. The hardness, elastic modulus, elastic strain to failure and resistance to plastic deformation were found to be maximum and the coefficient of friction was relatively low for the films with a carbon content of 62.5 at.\% due to the formation of nanocomposite of nanocrystalline $\mathrm{TiC}$ in an amorphous carbon matrix. These results are significant because, the effect of ion bombardment on the growing film is less in the pulsed DC and DC balanced magnetron co-sputtering technique (pulsed BMS) as compared to other techniques, and this can enhance the life time of coatings. Using this wide range composition dependent properties one can choose proper growth window for different applications like tribology, diffusion barriers, and corrosion resistance coatings.

\section{Acknowledgements}

MSRNK thanks the UGC Government of India for awarding Dr. D. S. Kothari Post-Doctoral Fellowship.

\section{References}

[1] W. Lengauer, Transition metal nitrides, carbides and carbonitrides, in: Ralf Riedel (Ed.), Hand Book of Ceramic Hard Materials, WILEY-VCH Verlag GmbH, Weinheim, 2000, pp. 202-248.

[2] M. Eizenberg, S.P. Murarka, Journal of Applied Physics 54 (1983) 31903194.

[3] M.A. Nicolet, Thin Solid Films 52 (1978) 415-443.

[4] S.K. Lee, C.-M. Zetterling, M. Ostling, J.-P. Palmquist, U. Jansson, Microelectronic Engineering 60 (2002) 261-268.

[5] F. Santerre, M.A. El Khakani, M. Chaker, J.P. Dodelet, Applied Surface Science 148 (1999) 24-33.

[6] J. Chmiola, C. Largeot, P.-L. Taberna, P. Simon, Y. Gogotsi, Science 328 (2010) 480-483.

[7] Z.Y. Zeng, J.P. Tu, X.H. Huang, X.L. Wang, J.Y. Xiang, Thin Solid Films 517 (2009) 4767-4771.
[8] P. Groot, J.G. Van der Laan, M. Mack, M. Dvorak, P. Huber, Journal of Nuclear Materials 179 (1991) 370-374.

[9] D.W. Flaherty, R. Alan May, S.P. Berglund, K.J. Stevenson, C.B. Mullins, Chemistry of Materials 22 (2010) 319-329.

[10] P.J. Kelly, R.D. Arnell, Vacuum 56 (2000) 159-172.

[11] J.M. Anton, B. Mishra, J.J. Moore, J.A. Rees, W.D. Sproul, Surface and Coatings Technology 201 (2006) 4131-4135.

[12] J. Deng, M. Braun, Surface and Coatings Technology 70 (1994) 49-56.

[13] E. Lewin, O. Wilhelmsson, U. Jansson, Journal of Applied Physics 100 (2006), 054303-1-054303-10.

[14] R.D. Arnell, P.J. Kelly, Surface and Coatings Technology 112 (1999) 170-176

[15] W.D. Sproul, Surface and Coatings Technology 49 (1991) 284-289.

[16] S.M. Rossnagel, J.J. Cuomo, Thin Solid Films 171 (1989) 143-156.

[17] D.M. Mattox, Handbook of Physical Vapour Deposition Processing: Film formation Adhesion, Surface Preparation and Contamination Control, Noyse Publications, New Jersey, 1998.

[18] R.D. Arnell, P.J. Kelly, J.W. Bradley, Surface and Coatings Technology 188-189 (2004) 158-163.

[19] B. Window, N. Savvides, Journal of Vacuum Science and Technology A 4 (1986) 453-456.

[20] J. Lin, J.J. Moore, B. Mishra, M. Pinkas, W.D. Sproul, Thin Solid Films 517 (2008) 1131-1135.

[21] T. Zehnder, J. Patscheider, Surface and Coatings Technology 133-134 (2000) 138-144.

[22] M. Kobayashi, Y. Doi, Thin Solid Films 54 (1978) 67-74.

[23] M. Magnuson, E. Lewin, L. Hultman, U. Jansson, Physical Review B 80 (2009), 235108-1-235108-7.

[24] E. Lewin, P.O.A. Persson, M. Lattemann, M. Stuber, M. Gorgoi, A. Sandell, C. Ziebert, F. Schafers, W. Braun, J. Halbritter, S. Ulrich, W. Eberhardt, L. Hultman, H. Siegbahn, S. Svensson, U. Jansson, Surface and Coatings Technology 202 (2008) 3563-3570.

[25] W.C. Oliver, G.M. Pharr, Journal of Materials Research 7 (1992) 1564-1583.

[26] S. Veprek, G.J. Maritza, Veprek-Heijman, P. Karvankova, J. Prochazka, Thin Solid Films 476 (2005) 1-29.

[27] A.A. Voevodin, S.V. Prasad, J.S. Zabinski, Journal of Applied Physics 82 (1997) 855-858.

[28] C.Q. Chen, Y.T. Pei, K.P. Shaha, J.Th.M. De Hosson, Journal of Applied Physics 105 (2009) 114314.

[29] D. Galvan, Y.T. Pei, J.Th.M. De Hosson, Surface and Coatings Technology 201 (2006) 590-598.

[30] A. Leyland, A. Matthews, Wear 246 (2000) 1-11. 